\title{
Prediction of Blast Pressure Change by a Mathematical Model ${ }^{*}$
}

\author{
By Naochika MIYASAKA, ,* Masayasu SUGATA, ${ }^{* * *}$ Yukiaki HARA ${ }^{* * * *}$ and \\ Shin-ichi KONDO****
}

\begin{abstract}
Synopsis
Simulation of the blast furnace condition based on a mathematical model is one of the means, by which the phenomena observed in a blast furnace, especially in the high temperature zone, are quantitatively understood. The means described above is as follows: In order to clarify the blast furnace conditions, the regions from the top of bed to the tuyere level are divided into five parts by considering dead-man, i.e. the indirect reduction zone, the smelting zone, the direct reduction zone, the tuyere zone and the raceway zone. In each zone, twelve simultaneous ordinary differential equations, consisting of the heat transfer and reaction rate equations, are set up. The rate equations for six kinds of chemical reactions and the equations concerning the flow of fluids, which are expected to occur in a blast furnace, have been obtained experimentally. Furthermore, a few parameters are determined, so as to agree the computed curves of pressure drop and temperature with those measured in an actual large blast furnace.

In the actual blast furnace, it occurs sometimes that the blast pressure increases abnormally and then the state of furnace becomes worse and finally serious. As the results of analysing such a case by the use of a mathematical model, the increase of the blast pressure could be predicted at the time about three hours before.
\end{abstract}

\section{Introduction}

Recently many mathematical models, expressing the phenomena found in a blast furnace kinetically, have been reported. A simulation model for the blast furnace's stack region proposed by Bogdandy and Wartmann ${ }^{1)}$ is that of a countercurrent moving bed reactor with hydrogen and ores. Using this model, the distribution of temperature and the reduction ratio of ores in the direction of stack region height were calculated. Koump ${ }^{2)}$ presented a mathematical model, i.e., a countercurrent moving bed reactor model, which was derived under the consideration of the reduction of ores with $\mathrm{CO}$ gas and the gasification reaction of coke. In this country Muchi, et al..$^{3,4)}$ proposed a detailed simulation model and estimated the effects of high temperature blast, humidity in the blast, oxygen enrichment and of high top pressure.

In the current work, a mathematical simulation model representing the conditions in the regions from the top of bed to the tuyere level has been derived under the consideration of "dead-man" in the lower part of furnace and it has been found from the results applied to the practical furnace that the blast pressure (an important index of operation) could be predicted regardless of the static model.

\section{Mathematical Model}

The mathematical model for a blast furnace consisted of a reactor model representing the flow and the change of materials and the rate equations for the reactions. In the reactor model representing the furnace conditions from the top of bed to the tuyere level, it is generally divided into three or four parts along the vertical direction of the furnace, namely the preheating zone, the indirect reduction zone and the smelting zone etc, while the horizontal direction is assumed to be constant. But the uniformity in the horizontal direction can hardly be assumed in the case of a large blast furnace, particularly in the lower part of the stack or the tuyere level. So the authors have made up the model by considering the "dead-man" in the center of the furnace. Figure 1 shows the details of the reactor model adopted. Definitions of each parts are described in the following sections.

\section{Reactor Model of a Blast Farnace}

1. Dead-man (1)

This part is in the center of the lower part of furnace and it is considered to be a fixed bed of coke at rest.

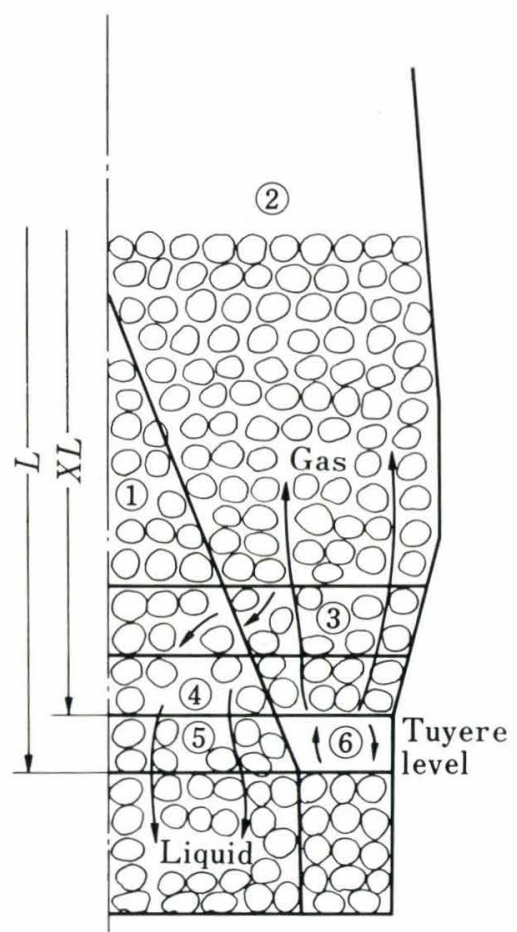
(1) Dead-man zone
(4) Direct reduction zone
(2) Indirect reduction zone
(5) Tuyere zone
(3) Smelting zone
6) Raceway zone

Fig. 1. Reactor model of blast furnace

* Originally published in Tetsu-to-Hagané, 58 (1972), 18, in Japanese. English version received March 8, 1974.

** Engineering, Machinary and Foundry Division, Nippon Steel Corp. (NSC), Otemachi, Chiyoda-ku, Tokyo 100.

*** Kimitsu Works, NSG., Hitomi, Kimitsu 299-11.

**** Fundamental Laboratory, NSC, Ida, Kawasaki 211. 
Size of the dead-man is estimated from the results of rod test for the practical furnace and of the experiment concerning the flow pattern of solid. The part outside the dead-man is defined as the effective cross section. In this section the charged materials descend uniformly (this experiment will be described later). Molten ores flow into the dead-man part from the smelting zone in the effective cross section and run down through the direct reduction zone-(4) and the tuyere zone-(6) in the dead-man part.

\section{Indirect Reduction Zone (2)}

This zone is the part from the top to the region whereat ores start to melt. In this zone ores are reduced by $\mathrm{CO}$ and $\mathrm{H}_{2}$ gases. These gases and the charged materials move only in the effective cross section of the blast furnace. The decomposition of limestone and the gasification of coke by $\mathrm{CO}_{2}$ and $\mathrm{H}_{2} \mathrm{O}$ are taken place in the relatively high temperature zone. For the calculation this zone is further divided into three subparts. In the first subpart, named indirect reduction zone-(1), the water-gas reaction and the Boudourd reaction are not in equilibrium. In the second subpart, which is the indirect reduction zone-(2), the water-gas reaction is in equilibrium but not the Boudourd reaction. And in the third subpart, the indirect reduction zone-(3), both reactions are in equilibrium.

\section{Smelting Zone (3)}

In this zone the charged materials except coke become to melt. The gases flow up in this zone (the effective cross section) and the molten materials run down in the dead-man.

\section{Direct Reduction Zone (4)}

The gases rise in the effective cross section and the molten oxides are reduced by carbon during the period of flowing down in the dead-man. Reaction heat, which is necessary for the direct reduction, is supplied from the gases outside the zone. The reason why gases do not flow in the dead-man zone is that the temperatures of melt and gases calculated from this assumption agree with the measured values.

\section{Tuyere Zone (5)}

In the same way as described in the case of direct reduction zone, the molten materials run down in the dead-man and the oxides in the melt are reduced by coke. Heat is supplied from the gases in the raceway which is outside of the dead-man.

\section{Raceway Zone (6)}

This is a circular space, wherein coke fallen from the effective cross section is burnt. Gases and coke are considered to be mixed perfectly in this part. In this mathematical model the dead-man is taken into account. Diameter of the dead-man was obtained from the rod test through the tuyere made during the operational run and its height was estimated from the following experiment.

Experimental apparatus was a semi-circular model having a reduced scale of one foutieth of the 2 nd blast furnace at Sakai Works. A semi-circular disk of various sizes was set in the center of the bottom. Solid particles were taken out through the gap between the disk and the wall and the flow pattern of solid in the apparatus was examined. As the solid particles, sea sand having the size of one fourtieth of the practical coke was used. For the examination of flow pattern coloured particles were added so as to form a thin layer. Photograph 1 shows an example of the experiment. Solid particles at the upper part of the apparatus move down uniformly, as the thickness of this layer becomes thinner on an average according to the extent of diameter. Flow of solid in the lower part can be divided into two parts, one is the part where solid flows down with a piston flow giving no effect of the disk and the other is the part where solid hardly flows down or stops to move due to the effect of the disk. Considering that the latter is corresponding to the dead-man, the relation between the diameter and the height is measured. Figure 2 shows the experimental results obtained. Empirical equation was derived by quoting the dimentional analysis proposed by Toyama. ${ }^{5)}$

$$
\left(L_{c} / D_{2}\right)=0.354\left\{\left(D_{2}-D_{3}\right) / D_{2}\right\}^{-0.356}
$$

(Notation are shown at the end of the report.) Height of the dead-man in the simulation model is calculated from the above equation. Though the experimental results showed that the shape of the top of dead-man was a round form, it was assumed to be a circular cone by taking the small difference of volume into account.

\section{Rate Equations}

Elementary reactions taken place in a blast furnace

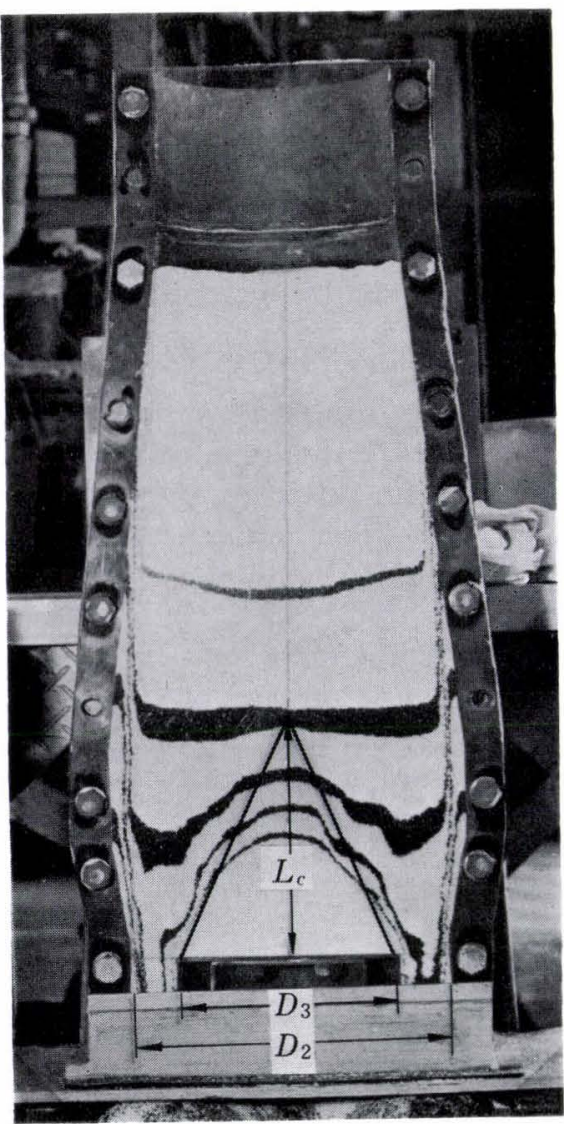

Photo, 1. Flow pattern of granular solid 


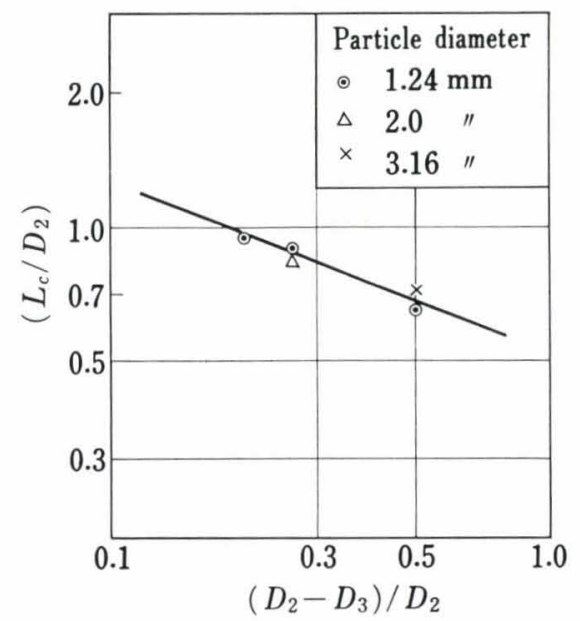

Fig. 2. Relationship between dead-zone height and its diameter

are the indirect reduction reaction by hydrogen and carbon monoxide, the gasification of coke by carbon dioxide and water vapour, the decomposition reaction of limestone, the direct reduction reaction of ferrous oxide in molten slag and the water-gas reaction. Rate equations for these reactions are obtained from the literatures or the experiments done by the authors.

1. Rate Equation of Indirect Reduction Reaction with Garbon Monoxide

Ores are reduced by carbon monoxide according to the following reaction:

$$
1 / 3 \mathrm{Fe}_{2} \mathrm{O}_{3}+\mathrm{CO} \underset{k_{11}^{\prime}}{\stackrel{k_{11}}{\rightleftarrows}} 2 / 3 \mathrm{Fe}+\mathrm{CO}_{2}
$$

Since this reaction occurs topochemically and the boundary film resistance in a blast furnace can be neglected because of high gas speed, the following equation is obtained.

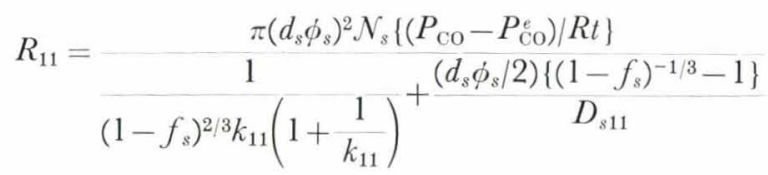

$\left(\mathrm{kg} \cdot \mathrm{mol} \mathrm{CO} / \mathrm{m}^{3} \cdot \mathrm{hr}\right)$

where, the chemical reaction constant $k_{11}$ is quoted from the literature. ${ }^{6}$

$$
k_{11}=\exp (5.8493-3460 / t)
$$

The effective diffusion coefficient $D_{s_{11}}$ can be obtained from the gaseous effective diffusibility and the diffusion coefficient. ${ }^{17}$

$$
\begin{aligned}
& D_{s 11}=\xi \cdot D_{\mathrm{CO}} \\
& D_{\mathrm{CO}}=\left(2.177 \times 10^{-6}\right) \cdot t^{1.833} / P_{\mathrm{T}}
\end{aligned}
$$

As the equilibrium constant $K_{11}$, the following values, were used depending on the temperature range and the reduction ratio of ores. ${ }^{3,7}$ )

$$
\begin{aligned}
& \kappa_{11}= \\
& \text { (1) } t \leqq 848^{\circ} \mathrm{C} \\
& \begin{array}{ll}
\exp (4.91+6235 / t) & \left(0 \leqq f_{s}<0.1111\right) \\
\exp (-0.7625+543.3 / t) & \left(0.1111 \leqq f_{s} \leqq 1.0\right)
\end{array}
\end{aligned}
$$

$$
\text { 2) } \begin{aligned}
t>848^{\circ} \mathrm{C} & \\
\exp (4.91+6235 / t) & \left(0 \leqq f_{s}<0.1111\right) \\
\exp (2.13-2050 / t) & \left(0.1111 \leqq f_{s}<0.3333\right) \\
\exp (-0.2642-216 / t) & \left(0.3333 \leqq f_{s} \leqq 1.0\right)
\end{aligned}
$$

\section{Indirect Reduction Rate of Ores by Hydrogen}

Ores are reduced by hydrogen according to the next equation.

$$
(1 / 3) \mathrm{Fe}_{2} \mathrm{O}_{3}+\mathrm{H}_{2} \underset{k_{12}^{\prime}}{\stackrel{k_{12}}{\rightleftarrows}}(2 / 3) \mathrm{Fe}+\mathrm{H}_{2} \mathrm{O}
$$

The rate equation for hydrogen can be expressed by the same form as that of $\mathrm{CO}$ gas.

$$
R_{12}=\frac{\pi\left(d_{s} \phi_{s}\right)^{2} \mathcal{N}_{s}\left\{\left(P_{\mathrm{H}_{2}}-P_{\mathrm{H}_{2}}\right) / R t\right\}}{\left(1-f_{s}\right)^{2 / 3} \cdot k_{12}\left(1+\begin{array}{c}
1 \\
K_{12}
\end{array}\right)}\left(\begin{array}{c}
\left(d_{s} \phi_{s} / 2\right)\left\{\left(1-f_{s}\right)^{-1 / 3}-1\right\} \\
D_{s 12} \\
\left(\mathrm{~kg} \cdot \mathrm{mol} \mathrm{H}_{2} / \mathrm{m}^{3} \cdot \mathrm{hr}\right) \ldots \ldots \ldots \ldots \ldots(3) \ldots \ldots \ldots
\end{array}\right.
$$

The rate constant and the equilibrium constant are as follows.

$$
\begin{aligned}
& k_{12}= \begin{cases}(102.78) \cdot t \cdot \exp (-7500 / t) & \left(t \leqq 848^{\circ} \mathrm{C}\right) \\
(82.50) \cdot t \cdot \exp (-7700 / t) & \left(t>848^{\circ} \mathrm{C}\right)\end{cases} \\
& D_{s 12}=\xi \cdot D_{\mathrm{H}_{2}} \\
& D_{\mathrm{H}_{2}}=\left(8.031 \times 10^{-6}\right) t^{1.833} / P_{\mathrm{T}} \\
& K_{12}= \\
& \text { (1) } t \leqq 848^{\circ} \mathrm{C} \\
& \exp (8.384+2546.5 / t) \quad\left(0 \leqq f_{s}<0.1111\right) \\
& \exp (2.700-3183 / t) \quad\left(0.1111 \leqq f_{s} \leqq 1.0\right) \\
& \text { 2) } t>848^{\circ} \mathrm{C} \\
& \exp (8.102+2065 / t) \quad\left(0 \leqq f_{s}<0.1111\right) \\
& \exp (8.356+8117 / t) \quad\left(0.1111 \leqq f_{s}<0.3333\right) \\
& \exp (1.451-2328 / t) \quad\left(0.3333 \leqq f_{s} \leqq 1.0\right)
\end{aligned}
$$

3. Gasification of Coke by Carbon Dioxide ${ }^{8)}$

Carbon in coke is gasified into $\mathrm{CO}$ by $\mathrm{CO}_{2}$. From the experiment concerning the gasification of fine coke, the rate of fractional gasification for such mixed gases as found in a blast furnace can be expressed by Eq. (4).

$$
\frac{d f_{c}}{d \theta}=\frac{k_{1} P_{\mathrm{CO}_{2}}+k_{4} P_{\mathrm{H}_{2} \mathrm{O}}}{1+k_{2} P_{\mathrm{CO}_{2}}+k_{3} P_{\mathrm{CO}}+k_{5} P_{\mathrm{H}_{2} \mathrm{O}}} \quad(1 / \mathrm{hr}) \ldots
$$

In order to obtain the rate equation for lump coke, the effective coefficient, which corrects the influence of diffusion in a particle, is required. This coefficient is determined from the comparison of the experimental results obtained by the gasification of various sizes of coke with those calculated from the above equation. The equation obtained for the gasification of coke by $\mathrm{CO}_{2}$ is :

$$
R_{21}=E_{f}\left(\begin{array}{c}
m_{c}^{o} \mathcal{N}_{c} \\
M_{c}
\end{array}\right)\left\{\begin{array}{c}
k_{1} P_{\mathrm{T}} y_{\mathrm{CO}_{2}} \\
1+P_{\mathrm{T}}\left(k_{2} y_{\mathrm{CO}_{2}}+k_{3} y_{\mathrm{CO}}+k_{5} y_{\mathrm{H}_{2} \mathrm{O}}\right.
\end{array}\right\}
$$$$
\left(\mathrm{kg} \cdot \mathrm{mol} \mathrm{CO} 2 / \mathrm{m}^{3} \cdot \mathrm{hr}\right)
$$

where,

$$
\begin{aligned}
& k_{1}=\exp (27.201-35900 / t) \\
& k_{2}=\exp (14.240-18350 / t)
\end{aligned}
$$




$$
\begin{aligned}
k_{3} & =10.3 \\
k_{5} & =\exp (29.588-36760 / t) \\
E_{f} & =\exp \{(\ln (0.15))(t-1073) / 300\}
\end{aligned}
$$

\section{Gasification of Coke by Water Vapour ${ }^{8)}$}

Gasification of coke by water vapour proceeds in the same way as in the case of carbon dioxide. The rate equation for this gasification is given by the following equation:

$$
R_{22}=E_{f}\left(\frac{m_{c}^{o} \mathcal{N}_{c}}{M_{c}}\right)\left\{\begin{array}{c}
k_{4} P_{\mathrm{T}} y_{\mathrm{H}_{2} \mathrm{O}} \\
1+P_{\mathrm{T}}\left(k_{2} y_{\mathrm{CO}_{2}}+k_{3} y_{\mathrm{CO}}+k_{5} y_{\mathrm{H}_{2} \mathrm{O}}\right)
\end{array}\right\}
$$$$
\left(\mathrm{kg} \cdot \mathrm{mol} \mathrm{H} \mathrm{H}_{2} \mathrm{O} / \mathrm{m}^{3} \cdot \mathrm{hr}\right)
$$

\section{Decomposition of Limestone}

Ordinally the rate-determining step for the decomposition of a lump limestone is considered as the heat transfer in a particle. But in the case of low partial pressure of $\mathrm{CO}_{2}$ as in the case of blast furnace, the rate of chemical reaction should be considered in addition to the heat transfer. ${ }^{9)}$ Generally the rate equation for the decomposition including both rate-determining steps is very complecate. It has therefore been used the rate equation for the decomposition which is derived by assuming that the rate of decomposition changes linearly with temperature according to the proposal made by Mamuro. ${ }^{10)}$ That is, the apparent beginning temperature of decomposition is assumed and the rate of decomposition increases linearly with increasing temperature above this point. Based on the foregoing assumption, the overall decomposition rate of limestone is expressed by the following equations: is as follows:

$$
-\left(\frac{1}{A_{o}} \frac{d n_{\mathrm{FeO}}}{d \theta}\right)=k_{a} a_{\mathrm{FeO}}
$$

For the practical usage, the activity of ferrous oxide must be expressed by the concentration of FeO. The activity of $\mathrm{FeO}$ measured by Samarin et al. ${ }^{12}$ at $1600^{\circ} \mathrm{C}$ is assumed to be able to apply at any temperature. In this case the activity of $\mathrm{FeO}$ can be expressed by this equation:

$$
a_{\mathrm{FeO}}=\left(\mathcal{N}_{\mathrm{FeO}}\right)^{0.55}
$$

for the operational slag composition. The rate equation for the direct reduction of $\mathrm{FeO}$ in a blast furnace becomes as follows:

$$
\begin{aligned}
R_{6} & =k_{6} a_{o}\left(\mathcal{N}_{\mathrm{FeO}}\right)^{0.55} \quad\left(\mathrm{~kg} \cdot \mathrm{mol} \mathrm{FeO} / \mathrm{m}^{3} \cdot \mathrm{hr}\right) \ldots \ldots(9) \\
k_{6} & =\exp (11.554-19980 / t)
\end{aligned}
$$

\section{Water-gas Reaction}

The equation is the following:

$$
\mathrm{H}_{2} \mathrm{O}+\mathrm{CO}=\mathrm{H}_{2}+\mathrm{CO}_{2}
$$

The rate equation of this reaction obtained by Moe ${ }^{13)}$ is the following:

$$
\begin{array}{r}
R_{7}=k_{7}\left(\begin{array}{c}
V_{s} \\
V_{\mathrm{T}}
\end{array}\right)(1-\varepsilon)\left(\begin{array}{c}
P_{\mathrm{T}} \\
0.082 t
\end{array}\right)^{2}\left(y_{\mathrm{CO}} \cdot v_{\mathrm{H}_{2} \mathrm{O}}-\frac{y_{\mathrm{CO}_{2} y_{\mathrm{H}_{2}}}^{K}}{K}\right) \\
\quad\left(\mathrm{kg} \cdot \mathrm{mol} \mathrm{CO} / \mathrm{m}^{3} \cdot \mathrm{hr}\right) \ldots \ldots \ldots(10) \\
K=\exp (-3.7176+4302.9 / t)
\end{array}
$$

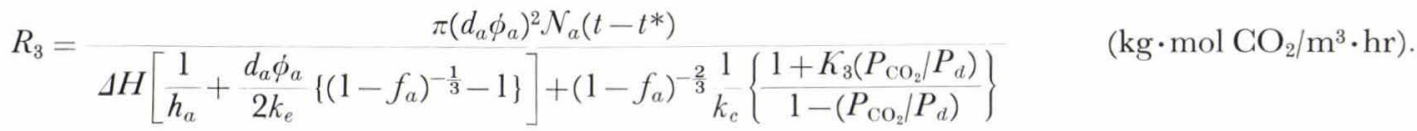

$$
k_{7}=\exp (23.81-4890 / t)
$$

where, $t^{*}$ is the beginning temperature of decomposition, $\Delta H_{3}$ the heat of decomposition, $h_{a}$ the surface heat transfer coefficient, $k_{e}$ the heat conductivity in a particles, $k_{c}$ the decomposition rate constant, $p_{d}$ the decomposition pressure of limestone and $k_{3}$ the equilibrium constant of carbon dioxide absorption. The values quoted from the literatures are as follows.

$$
\begin{aligned}
t^{*} & =780^{\circ} \mathrm{C} \quad\left(R_{3}=0 \text { at } t \leqq t^{*}\right) \\
\Delta H_{3} & =45400-4.50 t \\
h_{a} & =\frac{k_{f}}{\varepsilon\left(d_{a} \phi_{a}\right)}\left\{2.0+0.75\left(\frac{d_{a} \phi_{a} W_{f}}{\bar{\mu}_{f}}\right)^{1 / 2}\left(\frac{\bar{C}_{\bar{\mu}} \bar{\mu}_{f}}{\bar{M}_{f} \bar{k}_{f}}\right)^{1 / 3}\right\} \\
k_{c} & =2.25 \times 10^{-3} \\
p_{d} & =\exp \left\{20.3 \times 10^{3} \cdot(1 / 1170-1 / t)\right\} \\
k_{e} & =0.680 \\
k_{3} & =4.0
\end{aligned}
$$

\section{Direct Reduction of Ferrous Oxide in Slag}

Ferrous oxide in slag is considered to be mainly reduced at the surface of coke, as slag flows down in coke bed. According to the experimental results obtained $^{11)}$ by the authors, the reduction rate of ferrous oxide in slag is proportional to the activity of $\mathrm{FeO}$ in slag and to the reaction surface. The rate equation
This rate equation can only be applied to the indirect reduction zone-(1) in the upper part of blast furnace and the water-gas reaction is assumed to be in equilibrium for the other zones. It was comfirmed experimentally ${ }^{14}$ ) that the rate at high temperature was very fast.

\section{Equation for the Pressure Drop}

There is a well known equation derived by Carman and Kozenny ${ }^{15}$ ) for a fixed bed.

$$
\frac{\Delta P}{\Delta x}=f\left(\frac{\bar{\rho}_{f} u_{g}^{2}}{2 g_{c}}\right)\left(\frac{a_{\mathrm{t}}}{\varepsilon^{3}}\right)
$$

Since the value of Reynolds number in blast furnace is ranging from 100 to 500 , which is the range of turbulant flow, the friction factor $f$ can be given by the following equation.

$$
f=\frac{5}{R e}+\frac{0.4}{R e^{0.1}}
$$

Furthermore, the change in the porocity and the specific surface area of a fixed bed must be considered on account of the reduction degradation of ore. Kanbara 
and Fujita ${ }^{16}$ showed that the degradation ratio of sinter increased with increasing time of exposure to reducing gases, that is, the reduction ratio of sinter, and that it increased with the time remaining in the lower temperature range. This effect is inserted to the pressure drop equation as the functions of temperature and reduction ratio: $\left(a-b t+c f_{s}\right)$. The equation used for pressure drop is the following:

$$
\frac{\Delta P}{\Delta x}=f\left(\frac{\bar{\rho}_{f} u_{\theta}^{2}}{2 g_{c}}\right)\left(\frac{a_{\mathrm{t}}}{\varepsilon^{3}}\right)\left(a-b t+c f_{s}\right) \quad\left(\mathrm{kg} / \mathrm{m}^{3}\right)
$$

where, constants $a, b$ and $c$ depend on the kind of ore. Value of $a_{t}$ is determined as follows; when $\varepsilon$ is assumed to be constant, the number of particles existing in a cubic meter of fixed bed is shown by

$$
\mathcal{N}_{p}=(1-\varepsilon) / v_{p}
$$

where, $\mathcal{N}_{p}$ is the number of particles existing in a cubic meter of fixed bed and $v_{p}$ is the volume of a particle. So the surface area, $a_{t}$, is obtained from the surface area of a particle and the number of particles existing in a cubic meter of fixed bed. The mean particle surface area, which is calculated from each ratio of particles in the charged materials, is used as $\mathcal{N}_{p}$. When the value of $a, b$ and $c$ are $1.8,1.5 \times 10^{-3}$ and 3.0 respectively in the case of Tobata No. 3 blast furnace, the calculated value agreed with the measured one through the vertical probe. Though it is considered that these values in the equation depend on the kind of burdens, $a, b$ and $\varepsilon$ are constant and $a_{t}$ and $c$ are calculated every $2 \mathrm{hr}$ according to the ratio of charged blend and the equation: $(c=-5.867+33.33$ $v_{s} ; v_{s}$ is the sinter ratio).

The equation for the pressure drop of two phase countercurrent flow for liquid and gas has to be used in the smelting zone. But, because the equation is very complicated and has no sufficient accuracy, Eq. (12) is applied. And the pressure drop after the smelting zone is assumed to be equal to that of a fixed bed of coke. The value of the surface area of particles in a cubic meter of fixed bed is equal to that of coke, too. The term of correction $\left(a-b t+c f_{s}\right)$ is a unit, because the term of correction for the reduction degradation is not necessary after the smelting zone.

\section{Heat Transfer into Dead-man}

Mechanism of heat transfer is considered to be the same as that heat loss and the flux of heat transfer is added to the differential equations. And the heat transfer coefficient and the surface area, which are necessary for the calculation, are obtained by the following way. Assuming that the boundary of the dead-man and the effective cross section consist of coke, the heat transfer coefficient is calculated from Ranz's equation for coke particle and gas and the surface area of heat transfer is obtained by considering the irregularity of coke particles.

\section{Calculation Procedure of the Mathematical Model}

The situation of a blast furnace can be estimated on the basis of this model. This model has twelve variables, namely the mole fractions of $\mathrm{CO}, \mathrm{H}_{2}, \mathrm{CO}_{2}$ and
$\mathrm{H}_{2} \mathrm{O}$, temperatures of gas, ore, coke and molten ore, the reduction degree of ore, the gasification ratio of coke, the decomposition ratio of limestone and the molar number of liquid. And twelve dimensions of differential simultaneous equations can be obtained from the material balance, the heat balance and the energy balance for the pressure drop of the infinitisimal height in each reaction zone.

After many trial calculations, the calculation procedure shown in Fig. 3 was selected in the current work. The procedure is as follows:

(1) The initial condition for the top of furnace are set up from the operational data.

(2) Apparent equilibrium constant of water gas reaction is calculated from the gaseous composition of the top gas. When the value is less than that of the equilibrium constant obtained from the solid temperature, the calculation is started from the equations expressing the indirect reduction zone-(1).

(3) If the calculated result agrees well with the equilibrium constant of water gas reaction, this reaction is assumed to be in equilibrium. And then the equilibrium of Boudourd reaction is examined. If the calculated value is larger than that estimated from the solid temperature, that is, the Boudourd reaction is not in equilibrium, the calculation is made for the indirect reduction zone-(2).

(4) As if the apparent equilibrium constant is equal to or less than that calculated from the solid temperature at the beginning of calculation, the calculation using the indirect reduction zone -(2) because the solid temperature is ordinarily too low for the establishment of equilibrium in Boudourd reaction.

(5) When the calculation further proceeds, the apparent equilibrium constant becomes again equal to or larger than that calculated from the solid temperature. In this case the solid temperature is usually high enough for equilibration of Boudourd reaction. Thereafter the calculation proceeds using the equation for the indirect reduction zone-(3). Figure 4 shows the change of the apparent equilibrium constant in the case of calculation for Sakai No. 2 blast furnace.

(6) Assuming that solid starts to melt down at $1450^{\circ} \mathrm{C}$, the calculation is made by using the equations for the melting zone. The rate of melting is obtained from the heat transfering from gas to solid except the heat of reaction. The temperature of molten materials is assumed to be equal to the coke temperature.

(7) After the completion of melting, the calculation is made by using the equation for the direct reduction zone.

(8) When the distance from the top reaches to the upper part of the raceway, the equations for the raceway zone are used.

(9) At last the heat balance in the raceway zone is calculated. If the calculated gas temperature agrees with that calculated from the blast condition, the calculation is stopped. If not, the top gas temperature for the initial conditions is changed and the same calculation is executed.

Figure 5 shows the results calculated on the basis 


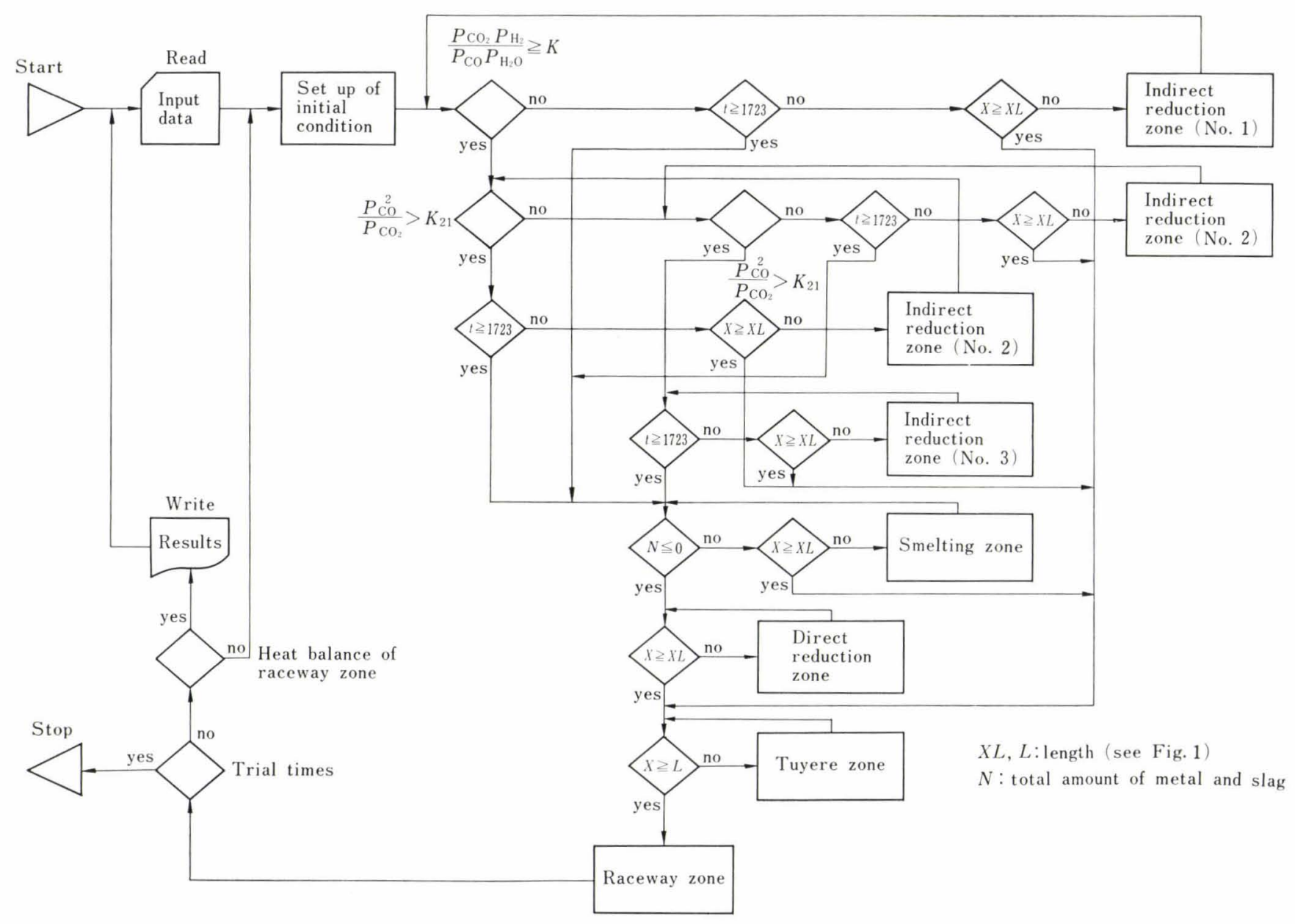

Fig. 3. Flow chart of calculation

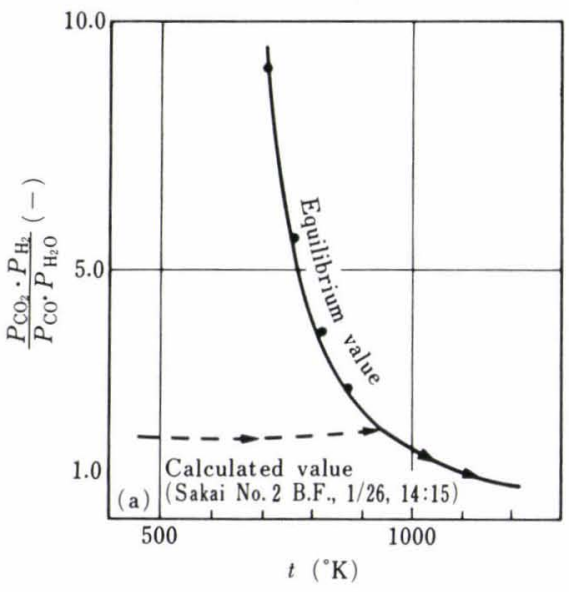

(a) Water gas shift reaction

(b) Boundoured reaction

Fig. 4. Explanation of calculating procedure

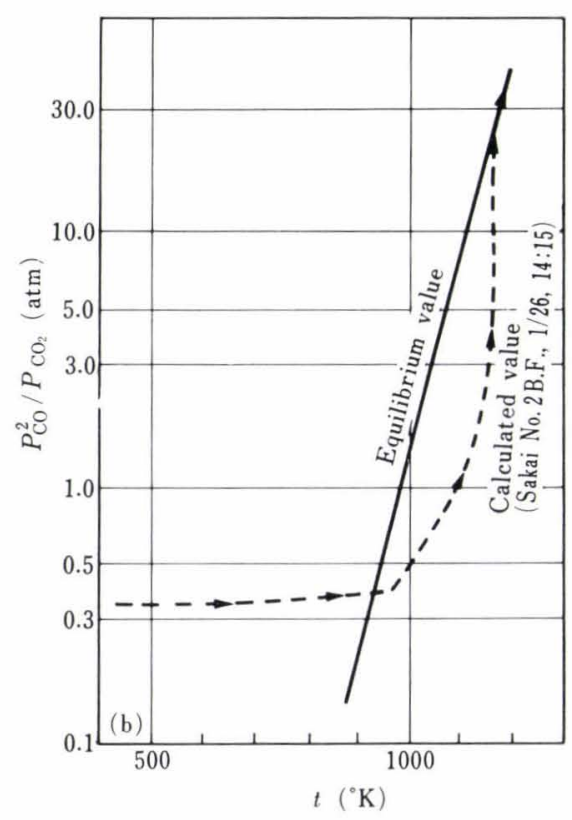

of this model, by using the operational data of Tobata No. 3 blast furnace in March, 1967. The measured values of temperature and pressure change with a vertical probe are also shown in Fig. 5 and this pressure change agrees with the calculated results. In the case of alternation of ore brand, the effective diffusion coefficient of gas was changed. For instance it was in- creased with the increase of charging ratio of pellet. Consequently, the reduction rate of ore increased. According to the alternation of ore brand, the mean size of ore should also be changed. As it was slightly difficult to change the ore size in this model, the correction term for the pressure drop equation was changed instead of changing the mean size of ore. In practice 


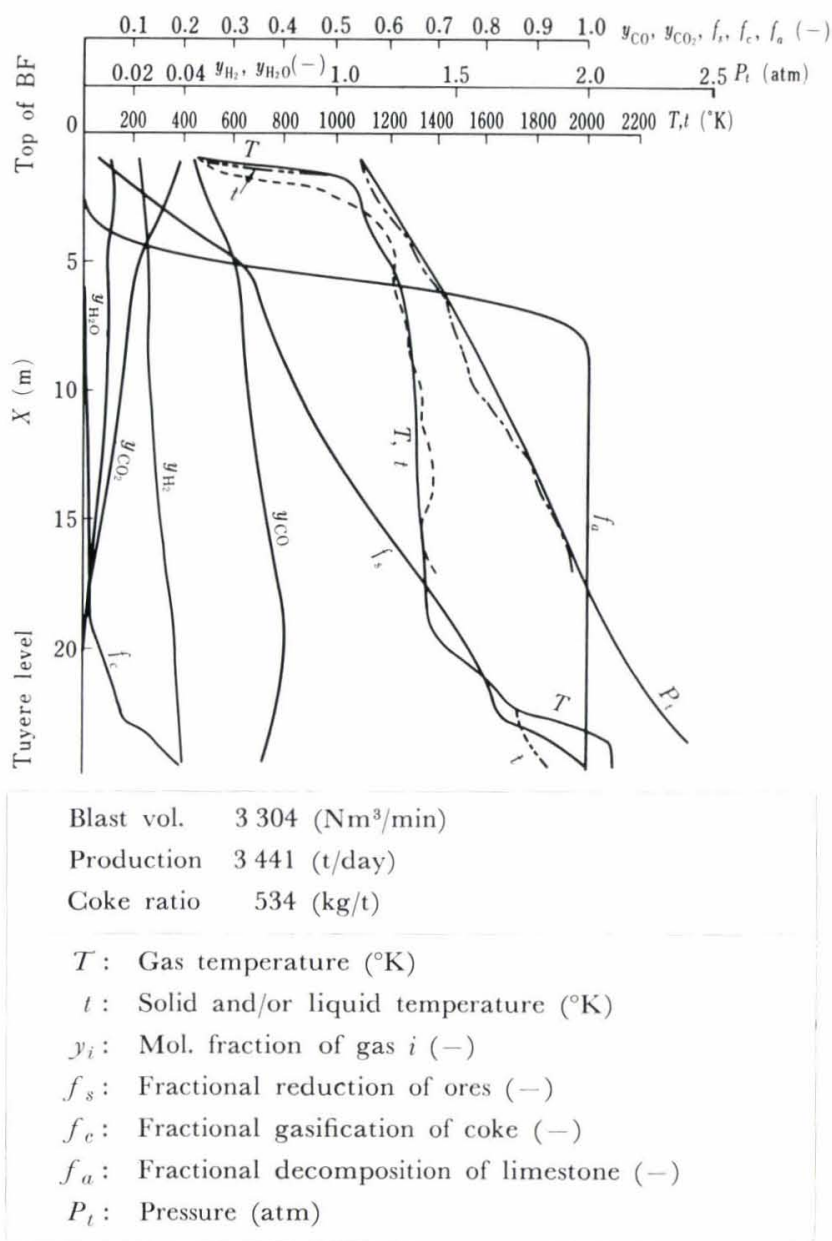

Fig. 5. Analytical results on Tobata No. 3 B.F.

the coefficient $c$ in Eq. (12) was increased with increasing sinter ratio by considering the degradation of sinter. The coefficients $a$ and $b$ were assumed to be constant in order to simplify the calculation.

\section{Prediction of the Change of Blast Pressure by the Mathematical Model}

At present many trials for the computer control of the blast furnace operation have been done on the basis of the mathematical model. The mathematical models adopted for this purpose are mostly derived from the heat balance. ${ }^{18)}$ Since the model for the permiability is scarcely studied, the possibility of predicting the permiability was examined by using the results calculated from the model mentioned above.

Figures 6 and 7 show the change in the values of blast pressure and top gas temperature (mean in $20 \mathrm{~min}$ ) measured in the periods of 25th to 27 th January and 3rd to 4th February. Normal blast pressure was about $2.1 \mathrm{~kg}-\mathrm{G} / \mathrm{cm}^{2}$ but at $20: 15$ in $25 \mathrm{th}$, 22: 15 in 26th, 23:15 in 3rd and 12:15 in 4th, the value of blast pressure was more than $2.3 \mathrm{~kg}-\mathrm{G} / \mathrm{cm}^{3}$, which was the operational limit of blast pressure. Since then the blast volume has been reduced. The rise of blast pressure observed in February 4th resulted in hanging. The blast pressures calculated at every one hour during this period are also shown in Figs. 6 and 7. Since the pressure used for the calculation is the sum of the pressure drop due to the enlargement of flow at tuyere and the blast pressure at raceway, the value used must nearly be equal to the pressure measured at bustle pipe. Assuming that the operational limit of blast pressure is $2.3 \mathrm{~kg}-\mathrm{G} / \mathrm{cm}^{2}$, the calculated value became to show the value more than $2.3 \mathrm{~kg}-\mathrm{G} / \mathrm{cm}^{2}$ at the time two or three hours in advance. If this trend is preferably applied to the practical operation, the rise of blast pressure can be predicted at least two or three hours before it happens. However, this mathematical model is the one derived for the steady state and therefore it is not possible to obtain the solution in such a case that a blast furnace is in an extremely unsteady state, i.e., just after a large lowering action of blast, at the time when the furnace is hung or slipped or at the time that abnormal number of charges was adopted.

As shown in the example of calculation, however, it is able to obtain the solution in the range of ordinary operational fluctuation. For instance the solution can be obtained under the condition that the fluctuation of the number of charges is less than $10 \%$. If the rise of blast pressure is predicted at least two or three hours in advance by the use of this model and if a proper action is taken at that time, it is possible to maintain the furnace in a relatively stable state without hanging or lowering action of blast.

On the other hand the reason why the change of furnace condition can be predicted on the basis of a steady state mathematical model is not clarified yet. However, the authors considered as follows: the solution of this model obtained from the operational data at a certain time coincides with the measured ones if the furnace is in a steady state. It is clearly shown by the results calculated for Tobata No. 3 blast furnace. Generally, the condition of blast furnace fluctuates more or less and so the calculated value does not agree with the measured one. The calculated value are rather considered to represent the operational data in a steady state at that time. Accordingly, if the dynamic characteristics of blast furnace is a first order delay system, the observed values at that moment will change to the calculated ones and both will agree after a certain period of time. In this case, however, it is necessary to assume that the initial conditions at top gas does not deviate so much from the steady state conditions. By checking this matter with the example of calculation, it is found that the range of condition, in which the solution exists and the prediction is possible, is not so wide. And as shown in Figs. 6 and 7, the calculated top gas temperature agreed with the observed one except the abnormal state. Main factors affecting the rise of blast pressure are the blast temperature, the number of charges and the amount of $\mathrm{FeO}$ in ores.

At present most of operational actions show the first order delay properties according to the simplified model. ${ }^{19)}$ So it is practical to use such a static model as the model adopted in this study, because it will take a quite long period of time to establish an exact dynamic model. Though the blast pressure fluctuation can 


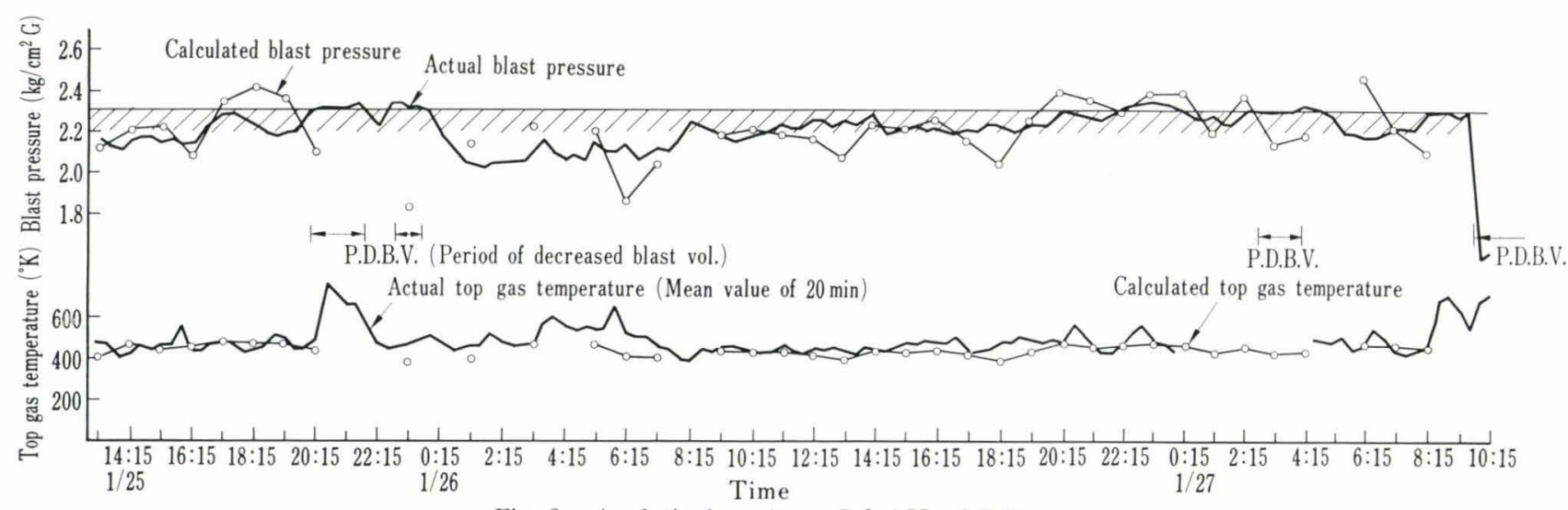

Fig. 6. Analytical results on Sakai No. 2 B.F.

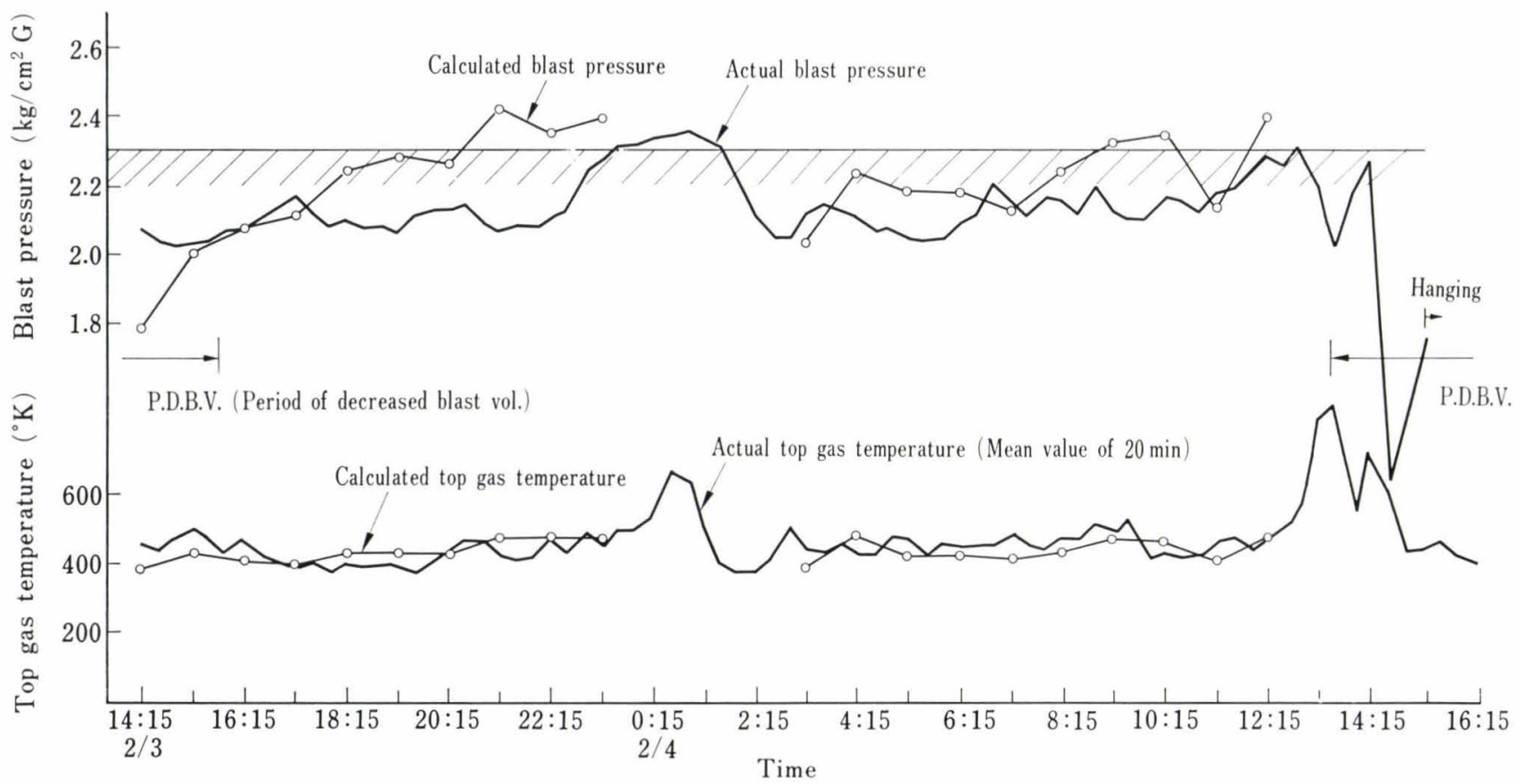

Fig. 7. Analytical results on Sakai No. 2 B.F.

be predicted by the static model, the amount of action is hardly be decided. Accordingly, the trial operations about the amount of action and the examination of exact dynamic characteristics are necessary in order to apply the present model for the practical operation.

Time required for the calculation is about $5 \mathrm{~min}$ for one condition when UNIVAC 1107 is used.

\section{Conclusion}

The mathematical model representing the furnace condition in the region from the top to the tuyere level, which is derived by considering the dead-man, has been established in the current work. As the result of applying this model to Sakai No. 2 blast furnace, the blast pressure fluctuation could be predicted at the time two or three hours before it happened. Although this model is the one for static state, it is possible to maintain the furnace in a stable state by the application of this model.

\section{Notation}

$A_{o}$ : reduction reaction surface of molten $\mathrm{FeO}$ by coke $\left(\mathrm{m}^{2}\right)$

$a$ : $\quad$ corrected coefficient of pressure drop (-) $a_{0}, a_{t}: \quad$ effective specific surface and total specific surface of fixed bed $\left(\mathrm{m}^{2} / \mathrm{m}^{3}\right)$

$a_{\mathrm{FeO}}$ : $\quad$ activity of $\mathrm{FeO}$ in slag (-)

$b, c$ : corrected coefficient of pressure drop $(-),(-)$

$C$ : mean specific heat of gas (kcal $/ \mathrm{kg}-\mathrm{mol}$ $D_{2}, D_{3}$ : diameters of hearth and deadman (m)

$D_{\mathrm{CO}}, D_{\mathrm{H}_{2}}$ : diffusion coefficients of $\mathrm{CO}$ and $\mathrm{H}_{2}$ $\left(\mathrm{m}^{2} / \mathrm{hr}\right)$

$D_{s_{11}}, D_{s_{12}}$ : effective diffusion coefficients of $\mathrm{CO}$ and $\mathrm{H}_{2} \quad\left(\mathrm{~m}^{2} / \mathrm{hr}\right)$

$d_{a}, d_{p}, d_{s}$ : diameters of limestone, particle and ore (m)

$E_{f}: \quad$ effective reaction coefficient of coke (-) $f: \quad$ friction coefficient (-)

$f_{a}, f_{c}, f_{s}$ : decomposition ratio of limestone, gasification ratio of coke and reduction ratio of ore $(-)$

$g_{c}: \quad$ gravitational factor $(-)$ 
$h_{a}:$

heat transfer coefficient between limestone and gas $\left(\mathrm{kcal} / \mathrm{m}^{2} \cdot \mathrm{hr} \mathrm{deg}\right)$

$K, K_{11}, K_{12}, K_{3}$ : equilibrium constants of water gas reaction, of reduction by $\mathrm{CO}$, of reduction by $\mathrm{H}_{2}$ and of $\mathrm{CO}_{2}$ adsorption on limestone (-)

$k_{1}, k_{4} ; k_{2}, k_{3}, k_{5}:$ rate constants of coke gasification $(1 / \mathrm{atm} \cdot \mathrm{hr} ; 1 / \mathrm{atm})$

$k_{6}, k_{7}: \quad$ rate constants of direct reduction reaction and of water gas reaction $(\mathrm{kg} \cdot \mathrm{mol} \mathrm{FeO} /$ $\mathrm{m}^{2} \cdot \mathrm{hr}, \mathrm{m}^{3} / \mathrm{kg} \cdot \mathrm{mol} \cdot \mathrm{hr}$ )

$k_{11}, k_{12}$ : rate constants of reduction by $\mathrm{CO}$ and $\mathrm{H}_{2} \quad(\mathrm{~m} / \mathrm{hr})$

$k_{a}$ : rate constant of molten $\mathrm{FeO}$ reduction based on $\mathrm{FeO}$ activity ( $\mathrm{kg} \cdot \mathrm{mol} \mathrm{FeO} /$ $\mathrm{m}^{2} \cdot \mathrm{hr}$ )

$k_{r}$ : rate constant of the decomposition of limestone $\left(\mathrm{kg} \cdot \mathrm{mol} \mathrm{CO} 2 / \mathrm{m}^{2} \cdot \mathrm{hr} \mathrm{deg}\right)$

$k_{e}$ : thermal conductivity of $\mathrm{CaO}$ (kcal/

$\mathrm{m} \cdot \mathrm{hr} \operatorname{deg}$ )

$k_{f}$ : mean thermal conductivity of gas (kcal/ $\mathrm{m} \cdot \mathrm{hr} \operatorname{deg}$ )

$L_{c}: \quad$ height of deadman $(\mathrm{m})$

$M_{c}: \quad$ molecular weight of gas (-)

$\bar{M}_{f}: \quad$ mean molecular weight of gas $(-)$

$m_{c}^{o}$ : $\quad$ initial carbon content in coke $(\mathrm{kg})$

$\mathcal{N}_{a}, \mathcal{N}_{c}, \mathcal{N}_{s}$ : numbers of particles of limestone, coke and ore $\left(1 / \mathrm{m}^{3}\right)$

$\mathcal{N}_{\mathrm{FeO}}: \quad$ corrected molar fraction of $\mathrm{FeO}$ in slag $(-)$

$\mathcal{N}_{p}: \quad$ number of particles existing in a cubic meter of fixed bed

$n_{\mathrm{FeO}}: \quad \quad$ kilogram mole of $\mathrm{FeO} \quad(\mathrm{kg} \cdot \mathrm{mol} \mathrm{FeO})$

$P_{\mathrm{CO}}, P^{e}{ }_{\mathrm{CO}}: \quad$ partial pressure of $\mathrm{CO}$ and equilibrium partial pressure of reduction by $\mathrm{CO}$ (atm)

$P_{\mathrm{CO}_{2}}: \quad$ partial pressure of $\mathrm{CO}_{2} \quad$ (atm)

$P_{d}: \quad$ decomposition pressure of $\mathrm{CaCO}_{3}$ (atm)

$P_{\mathrm{H}_{2}}, P^{e}{ }_{\mathrm{H} 2}:$ partial pressure of $\mathrm{H}_{2}$ and equilibrium partial pressure of reduction by $\mathrm{H}_{2}$ (atm)

$P_{\mathrm{H} 2 \mathrm{O}}: \quad$ partial pressure of water (atm)

$P_{\mathrm{T}}: \quad$ total pressure (atm)

$R: \quad$ gas constant $\left(\mathrm{m}^{3} \mathrm{~atm} / \mathrm{kg} \cdot \mathrm{mol} \mathrm{deg}\right)$

$R e: \quad \quad$ Reynolds number $\left(=u_{g} \bar{\rho}_{f} / a_{t} \bar{\mu}_{f}\right) \quad(-)$

$R_{3}$ : decomposition rate of limestone $(\mathrm{kg} \cdot \mathrm{mol}$ $\mathrm{CO}_{2} / \mathrm{m}^{3} \mathrm{hr}$ )

$R_{6}, R_{7}$ : rates of direct-reduction reaction and water-gas reaction $\left(\mathrm{kg} \cdot \mathrm{mol} \mathrm{FeO} / \mathrm{m}^{3} \cdot \mathrm{hr}\right.$, $\mathrm{kg} \cdot \mathrm{mol} \mathrm{CO} / \mathrm{m}^{3} \cdot \mathrm{hr}$ )

$R_{11}, R_{12}$ : rates of indirect reduction reaction by $\mathrm{CO}$ and $\mathrm{H}_{2} \quad\left(\mathrm{~kg} \cdot \mathrm{mol} \mathrm{CO} / \mathrm{m}^{3} \cdot \mathrm{hr}, \mathrm{kg} \cdot \mathrm{mol}\right.$ $\left.\mathrm{H}_{2} / \mathrm{m}^{3} \cdot \mathrm{hr}\right)$

$R_{21}, R_{22}: \quad$ gasification rates of coke by $\mathrm{CO}_{2}$ and $\mathrm{H}_{2} \mathrm{O}$ $\left(\mathrm{kg} \cdot \mathrm{mol} \mathrm{CO} \mathrm{CO}_{2} / \mathrm{m}^{3} \cdot \mathrm{hr}, \mathrm{kg} \cdot \mathrm{mol} \mathrm{H}_{2} \mathrm{O} / \mathrm{m}^{3} \cdot \mathrm{hr}\right.$ )

$T, t: \quad$ temperatures of gas and solid melt $\left(\mathrm{K}^{\circ}\right)$

$t^{*}$ : beginning temperature for the decomposition of limestone $\left({ }^{\circ} \mathrm{K}\right)$

$u_{q}: \quad$ linear velocity $(\mathrm{m} / \mathrm{hr})$

$V_{s}, V_{\mathrm{T}}: \quad$ volumetric velocities of ore and solid $\left(\mathrm{m}^{3} / \mathrm{hr}\right)$

$v_{s}: \quad$ sinter ratio in charged materials $(-)$
$W_{f}: \quad$ mass velocity of gas $\left(\mathrm{kg} / \mathrm{m}^{2} \mathrm{hr}\right)$

$x$ : distance from stock line (m)

$y_{\mathrm{CO}}, y_{\mathrm{CO}_{2}}, y_{\mathrm{H}_{2}}, y_{\mathrm{H}_{2} \mathrm{O}}, y_{\mathrm{N}_{2}}$ : molar fractions of $\mathrm{CO}, \mathrm{CO}_{2}$,

$\mathrm{H}_{2}, \mathrm{H}_{2} \mathrm{O}$ and $\mathrm{N}_{2}$ (-)

$\mathrm{SH}_{3}$ : heat of decomposition of limestone (kcal/ $\mathrm{kg} \cdot \mathrm{mol} \mathrm{CO}_{2}$ )

$\Delta P: \quad$ pressure drop $\left(\mathrm{kg} / \mathrm{cm}^{2}\right)$

$\varepsilon: \quad$ porocity of fixed bed $(-)$

$\theta: \quad$ hour (hr)

$\bar{\mu}_{f}: \quad$ viscosity of gas $(\mathrm{kg} / \mathrm{m} \mathrm{hr})$

$\xi: \quad$ effective diffusivity in particle $(-)$

$\bar{o}_{f}$ : density of gas $\left(\mathrm{kg} / \mathrm{m}^{3}\right)$

$\phi_{a}, \phi_{s}$ : shape factors of limestone and ore (-)

\section{REFERENCES}

1) L. v. Bogdandy and R. Wartmann: Arch. Eisenhüttenw., 56 (1965) 221.

2) V. Koump, R. H. Tien, R. G. Olsson and T. F. Perzah: Process Simulation and Control in Iron and Steelmaking, J. M. Uys and H. L. Bishop, ed., Gordon \& Breach, Science Publishers Inc., New York, (1966) 125.

3) J. Yagi, K. Sasaki, and I. Muchi: Tetsu-to-Hagané, 54 (1968), 1019.

4) J. Yagi, K. Sasaki, and I. Muchi: Tetsu-to-Hagané, 54 (1968), 1032 .

5) S. Toyama: Report of National Chemical Laboratory for Industry, 58 (1963), 93.

6) I. Muchi, J. Yagi, K. Tamura and A. Moriyama: J. JIM, 30 (1966), 826.

7) Y. Hara, M. Tsuchiya and S. Kondo: Tetsu-to-Hagané, $\mathbf{5 5}$ (1969), 1297.

8) N. Miyasaka and S. Kondo: Tetsu-to-Hagané, 54 (1968), 1427.

9) Y. Hara: Trans. ISIJ, 8 (1968), 97.

10) T. Mamuro and J. Kitagawa: Proceedings of the 32nd Annual Meeting on Chemical Engineering, The Society of Chemical Engineering, Tokyo, (1967), 253.

11) S. Kondo and M. Sugata: The 54th Committee of Japan Society for the Promotion of Science 54-1163 (1970).

12) A. M. Samarin, A. W. Poliakov and L. A. Shvartsman: Izu. Akad, Nauk. SSSR, 12 (1949), 1639.

13) J. M. Moe: Chem. Eng. Prog., 58 (1962) 3, 33.

14) S. Kondo, Y. Hara and N. Miyasaka: The 54th Committee of Japan Society for Promotion of Science 54-1098 (1968).

15) P. C. Carman: Trans. Inst. Chem. Engrs., 15 (1937), 150.

16) H. Kanbara, K. Fujita and Y. Okikawa: Technical Report of Fuji Steel, 15 (1966), 89.

17) Chemical Engineer's Hand-book, Japan (The Society of Chemical Engineering, Japan) Maruzen, 68, 135.

18) S. Horie, Y. Yamamoto and K. Miyashita: Tetsu-to-Hagané, 57 (1971), 125.

19) I. Muchi and M. Horio: The 54th Committee of Japan Society for the Promotion of Science 54-1192 (1971).

\section{Discussions}

Masayuki Horio (Nagoya University)

(1) If gas cannot flow in the dead-man, the deadman should be cooled. How is the reaction heat supplied to this part?

(2) I think that the effect of the dead-man is mainly to rise the temperature of melt. How high is the temperature of melt at the tuyere level?

\section{Authors}

(1) Reaction heat in the dead-man is assumed to 
be supplied by the gas flowing outside surface of the dead-man.

(2) Temperature of the melt at tuyere level is about $1690^{\circ} \mathrm{C}$ in the case of Tobata No. 3 blast furnace.

\section{Tsutomu Fukushima (Nippon Kokan K. K.)}

Why is it assumed that gas does not flow in the dead-man and that the melting zone exists above the direct reduction zone?

\section{Authors}

Because the temperatures of melt and gas agree with the measured values. Melting temperature of sinter is assumed to be about $1450^{\circ} \mathrm{C}$ from the experiment and the height required to melt is about $30 \mathrm{~cm}$. For the simplification of the model, the indirect reduction is assumed to occur in the melting zone.

\section{Yoshikazu Kuwano (Tokyo University)}

(1) I understand that the reduction rate is deter- mined on the basis of the experimental results. What conditions are adopted for the experiments?

(2) How do you estimate the porosity for the calculation of pressure drop and what is the extent of porosity in the melting zone?

\section{Authors}

(1) It is not possible to carry out the experiment under the same flow rate as in the blast furnace operation. Therefore, by analysing the experimental data under the condition of mixed rate-determining step, the reaction rate constant and the intra-diffusion coefficient are obtained. The reaction rate in the blast furnace is then estimated from these values.

(2) For the simplification of the model, the porosity is assumed to be constant at any part of the furnace. As the equation for the pressure drop in the melting zone, the one for two phases should be used. In this study, Carman-Kozenney's equation is used, since there is not so much difference between the calculated results. 